\title{
Arthritis and antinuclear antibodies (ANA) with inherited deficiency of the sixth component of complement (C6)
}

\author{
ELIZABETH REINITZ, ${ }^{1}$ MARISSA LAWRENCE ${ }^{1}$ BETTY DIAMOND,${ }^{1} 2$ \\ HAROLD KEISER, ${ }^{1}$ AND CHESTER ALPER ${ }^{3}$
}

From the ${ }^{1}$ Division of Rheumatology and ${ }^{2}$ Department of Microbiology and Immunology, Albert Einstein College of Medicine, Bronx, New York; and the ${ }^{3}$ Children's Hospital Medical Center, Harvard Medical School, Boston, Massachusetts

SUMMARY We report here the case of a woman with joint pains found to have antinuclear antibodies and undetectable serum haemolytic complement. Investigation of her and her family members showed an inherited deficiency of C6.

While numerous reports of genetic deficiencies of isolated complement components have appeared in the literature, often their clinical and immunological significance remains unclear. Deficiencies of the early components, $\mathrm{C} 1, \mathrm{C} 4$, and $\mathrm{C} 2,{ }^{1}{ }^{2}$ have been associated with systemic lupus erythematosus (SLE) and other diseases thought to be mediated by immune complexes. Patients with deficiencies of $\mathrm{C} 3$ and late complement components have been found to be at increased risk for infections, predominantly disseminated neisserial infections in those with $\mathrm{C} 6$, C7, or C8 deficiency. ${ }^{3}$ More recently, patients with late complement component deficiencies with $\mathrm{SLE}^{4}$ and discoid lupus with Sjögren's syndrome ${ }^{5}$ have been reported, though these may represent chance associations.

\section{Materials and methods}

Sera were stored and shipped at $-70^{\circ} \mathrm{C}$. Antinuclear antibodies were detected by routine indirect immunofluorescence on mouse kidney sections. Total haemolytic complement was assayed as described by Kent and Fife. ${ }^{\circ}$ Normal values range from 150 to 250 units. Anti-DNA antibody levels were sought by counterimmunoelectrophoresis. ${ }^{8}$ Anti-DNA antibody levels were determined by Millipore filter

Accepted for publication 18 October 1985.

Correspondence to Dr Elizabeth Reinitz, 1165 Morris Park Avenue. Bronx. New York 10461. USA. assay as described by Ginsberg and Keiser. ${ }^{7}$ Complement component assays were performed by Cordis Laboratories (Miami, Florida) using two functional methods. With the microtitre plate assay a fourfold or greater difference between the reference specimen titre and the subject's specimen titre is significantly abnormal. A twofold difference is suggestive but not conclusive of an abnormal value. With the test tube method a difference of $50 \%$ or more is significant, and a difference of $15-50 \%$ is suggestive of an abnormal value. Typing of C6 was performed by electrofocusing as described by Hobart et al' and of C7 by the method described by Hobart and Lachmann. ${ }^{\prime \prime \prime}$

\section{Case report}

A 50 year old woman presented who had had pain and stiffness in her right elbow for three weeks, in her left knee for three months, and stiffness in her proximal interphalangeal joints for several months. She tired easily and complained of a generalised malaise but denied fever, chills, and weight loss. She had had allergic asthma in the past but was not troubled by this in recent years. She was menstruating and had smoked one packet of cigarettes a day for 30 years. She was taking no medications. She had had no treatment in hospital except for two unremarkable pregnancies.

A physical examination showed her to be within 
Table 1 Complement component assays performed on the serum of the proband by the microtitre plate assay.

\begin{tabular}{lcc}
\hline $\begin{array}{l}\text { Complement } \\
\text { component }\end{array}$ & Proband's serum & Control serum \\
\hline C1 & 64000 & 64000 \\
C2 & 24000 & 24000 \\
C3 & 3200 & 3200 \\
C4 & 4800 & 4800 \\
C5 & 32000 & 32000 \\
C6 & 6 & 32000 \\
C7 & 24000 & 48000 \\
C8 & 24000 & 24000 \\
C9 & 12000 & 12000 \\
\hline
\end{tabular}

normal limits except for minimal effusions at the right elbow and left knee, with mild tenderness, no warmth, erythema, or crepitus. There was a full range of motion at all the joints.

Laboratory examination was significant for a normal complete blood count; erythrocyte sedimentation rate $3 \mathrm{~mm} / 1 \mathrm{st} \mathrm{h}$; normal liver and renal function tests and uric acid; ANA1+; latex fixation rheumatoid factor negative; total haemolytic complement undetectable; anti-DNA antibodies normal; anti-extractable nuclear antigen antibodies negative; urinalysis normal. Courses of nonsteroidal anti-inflammatory agents did not alleviate her symptoms. Prednisone $15 \mathrm{mg}$ daily quickly resulted in clinical improvement, but the total haemolytic complement remained undetectable. Prednisone was tapered rapidly and discontinued. She remained well.

FAM I LY H IS TORY

The proband (case No 1) is one of five daughters of case No 2 and his deceased wife. Case 2 has a 12 year history of hypertension, which has been treated with hydrochlorothiazide and propranolol, and has had three strokes since 1978. Case No 3, the maternal uncle, has had gout since 1975. Of the proband's sisters, one (case 4) has had a history of anaemia since childhood, another (case 5) has thalassaemia minor, and the other two (cases 6 and 7) are healthy and have no significant medical histories. The proband's son, not available for testing, had a 'stroke' at age 20 with no residual neurological deficit, and her daughter (case 8) is healthy.

\section{Results}

Since the total haemolytic complement remained undetectable in the proband's serum, assays for functional complement components were performed on her serum by the microtitre assay. Results are shown in Table 1. After these results were obtained the sera of other family members were studied.

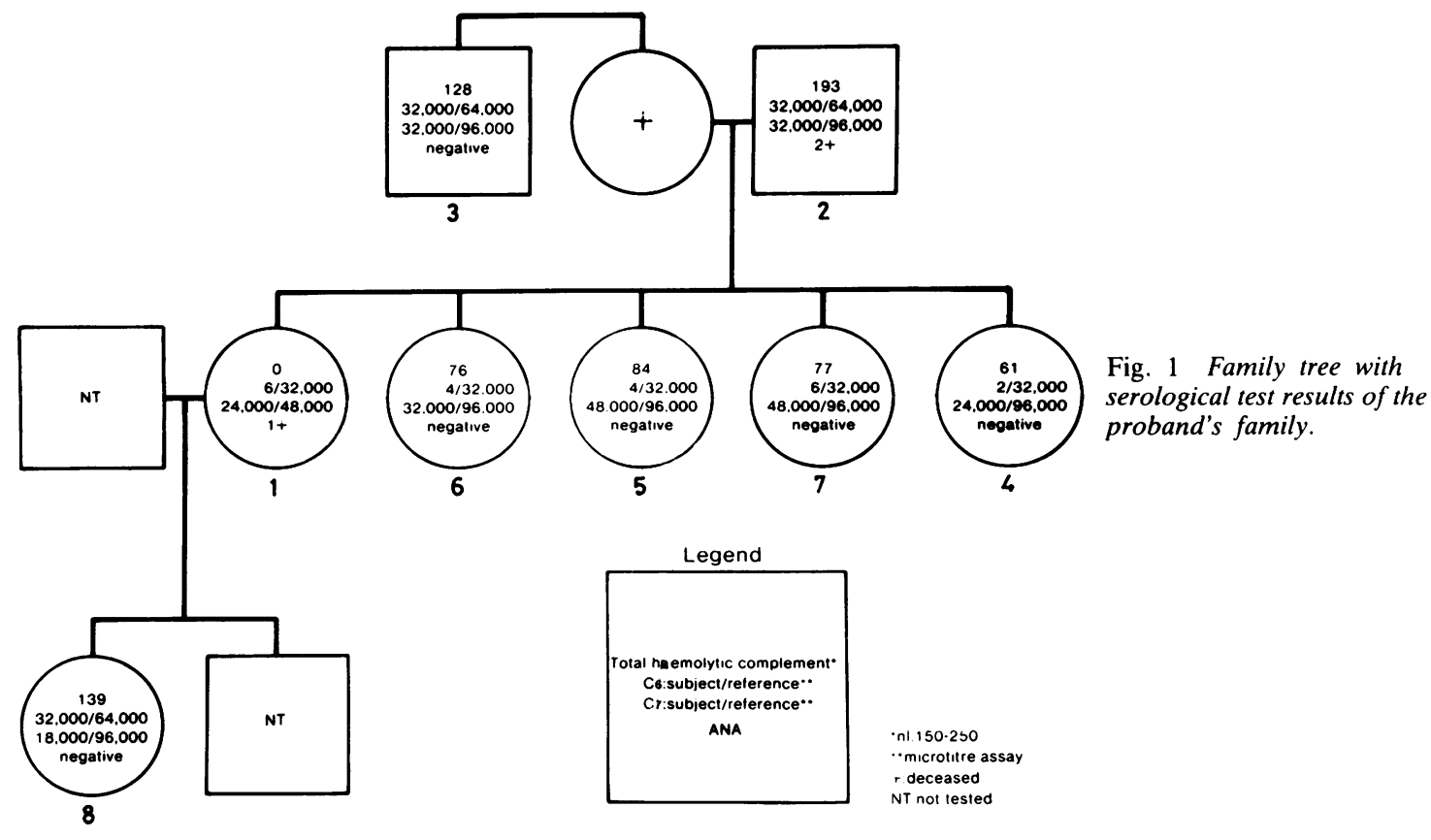


Table 2 Test tube assays for C6 and C7 on the sera of three family members

\begin{tabular}{|c|c|c|c|c|}
\hline \multirow{2}{*}{$\begin{array}{l}\text { Case } \\
\text { No }\end{array}$} & \multicolumn{2}{|l|}{ C6 } & \multicolumn{2}{|l|}{ C7 } \\
\hline & Subject & Control & Subject & Control \\
\hline 3 & 28000 & 93000 & 87000 & 210000 \\
\hline 2 & 45000 & 93000 & 110000 & 210000 \\
\hline 8 & 45000 & 93000 & 110000 & 210000 \\
\hline
\end{tabular}

The family tree and the serology results are shown in Fig. 1. Complement component assays shown on this figure were performed by the microtitre plate assay. Because several of the $\mathrm{C} 7$ levels fell in the lower than normal range, but not in the conclusively low range, some sera were also assayed by the test tube method. Results are shown in Table 2.

Ouchterlony immunodiffusion studies showed that the proband's serum lacked immunochemical $\mathrm{C} 6$ as did the serum of all her sisters. Immunochemically and functionally detectable C6 was found in serum from the proband's father (case 2) and daughter (case 8) (C6 A allotype) and maternal uncle (case 3) (C6 B allotype). All subjects' sera contained immunoprecipitable $\mathrm{C} 7$ which on isoelectric focusing was the C71 allotype.

The proband's complement profile had levels suggestive of partial C7 deficiency, together with the C6 deficiency. Family testing showed that only one sister (case No 4) had a conclusively reduced level of $\mathrm{C} 7$ by the microtitre assay performed by Cordis laboratories. Other family members tested had levels suggestive of $\mathrm{C} 7$ deficiency but did not meet criteria for conclusive diagnosis. Three of the sera (case Nos 2, 3, and 8) were also tested by the test tube assay for $\mathrm{C} 7$, and one of these (case No 3) showed conclusive C7 deficiency by this method.

\section{Discussion}

We have shown that members of this family have an inherited deficiency of C6. Polymorphism for human $\mathrm{C} 6$ has been described by Hobart et al, who found two major alleles, $\mathrm{A}$ and $\mathrm{B}$, and some much rarer alleles. ${ }^{9}$ The inheritance pattern is autosomal codominant. Heterozygous genetic deficiency of C6 seems to be due to a null allele. ${ }^{11}$ It is likely that the proband's father, maternal uncle, and daughter (cases 2, 3, and 8) are heterozygous for genetic deficiency of C6. The proband's mother could have been heterozygous or homozygous for C6 deficiency. The proband and her sisters are all homozygous deficient.

The most common $\mathrm{C} 7$ variant is $\mathrm{C} 71,{ }^{12}$ which was found antigenically in sera from all seven members of this family tested. The results of functional quantification of $\mathrm{C} 7$ are consistent with a partial genetic deficiency of $\mathrm{C} 7$ in at least two of the family members.

It is possible. therefore, that this family shares inherited defects in $\mathrm{C} 6$ and $\mathrm{C} 7$, the $\mathrm{C} 6$ deficiency inherited from the proband's maternal and paternal sides, while the $\mathrm{C} 7$ deficiency possibly inherited only from her maternal side. It is thought that $\mathrm{C} 6$ and $\mathrm{C} 7$ are products of tandem gene duplication since the genes are closely linked and their products (C6 and C7) have similar physiochemical and functional characteristics. ${ }^{13}$ By routinely screening sera for complement deficiency, Lachman and colleagues discovered a subject with subtotal deficiencies of both $\mathrm{C} 6$ and $\mathrm{C} 7 .^{13}$ Their subject, aged 67 at the time of discovery, had no history of increased susceptibility to infections or of any disease thought to be immune complex mediated. Glass et al have described a family in which six of 29 individuals tested were found to have both $\mathrm{C} 6$ and $\mathrm{C} 7$ deficiency. ${ }^{11}$ In that family no individual had C6 deficiency without C7 deficiency, or vice versa.

Complement component deficiencies have been found in healthy subjects. It remains unclear whether the genetic complement component deficiency plays any part in our proband's mild illness at age 50 . Her sisters, who have the same complement component deficiencies, have not had similar symptoms or any other conditions that are attributable to complement deficiency. As more subjects with complement component deficiency are described the disease associations should become clearer. The clinician should maintain a high index of suspicion for an inherited complement component deficiency when the complement level seems lower than expected for the clinical situation or is not improving along with clinical parameters with treatment.

\section{References}

1 Pondman K W. Stoop S W. Cormane R H. Hannema A J. Abnormal $\mathrm{Cl}$ in a patient with SLE [Abstract]. J Immunol 1968: 101: 811A.

2 Agnello V. Complement deficiency states. Medicine (Baltimore) 1978: 57: 15 .

3 Petersen B H. Lee T J. Snyderman R. Brooks G F. Neisseria meningitidis and Neisseria gonorrhoea bacteremia associated with C6. C7, or C8 deficiency. Ann Intern Med 1979; 90: 917-20)

4 Tedesco F. Silvani C M. Agelli M. Giovanetti A M. Bombardieri S. A lupus-like syndrome in a patient with deficiency of the sixth component of complement. Arthritis Rheum 1981: 24: $1438-40$.

5 Trapp R G. Mooney E. Hussain 1, Coleman T H. Forristal J. Herman J H. Hereditary complement (C6) deficiency with discoid lupus/Sjögren`s syndrome [Abstract]. Arthritis Rheum 1980; 23: 757 . 
6 Kent J, Fife E. Precise standardization of reagents for complement fixation. Am J Trop Med Hyg 1963; 12: 103-12.

7 Ginsberg B, Keiser H. A Millipore filter assay for antibodies to native DNA in sera of patients with systemic lupus erythema tosus. Arthritis Rheum 1973; 16: 199-207.

8 Keiser H D. Weinstein J. The detection and identification of antibodies to saline extractable nuclear antigens by counter immunoelectrophoresis. Arthritis Rheum 1980; 23: 1026-35.

9 Hobart M J. Lachmann P J, Alper C A. Polymorphism of human C6. In: Peeters H. ed. Protides of the biological fluids. New York: Pergamon. 1975; 22: 575-80.
10 Hobart M J, Lachmann P J. Allotypes of complement components in man. Transplant Rev 1976; 32: 26-42.

11 Glass D, Raum D, Balavitch D, et al. Inherited deficiency of the sixth component of complement: a silent or null gene. J Immunogenet 1978: 120: 538-41.

12 Hobart M J. Joysey V, Lachmann P J. Inherited structural variation and linkage relationships of C7. J Immunogenet 1978: 5: 157-63.

13 Lachmann P J, Hobart M J Woo. P. Combined genetic deficiency of C6 and C7 in man. Clin Exp Immunol 1978; 33: 193-203. 